\title{
Selecting optimum railway track using GIS techniques
}

\author{
Amjed Al-Hameedawi ${ }^{1,}{ }^{*}$, Mohammed Salih ${ }^{1}$, Haidar Mohammed ${ }^{1}$, and Maher Hassan ${ }^{2}$ \\ ${ }^{1}$ Building and Construction Engineering Department, University of Technology, Baghdad, Iraq \\ ${ }^{2}$ College of Engineering, University of Karbala, Karbala, Iraq
}

\begin{abstract}
This paper mainly aims at analysing and selecting the best railway route within the Karbala City. The significance of having suitable locations for railway route is recognized as a crucial element in the pursuit to improve the quality of public transport in general. This paper uses technique based on bridging the gap between all the criteria to determine suitable location for the railway. It was also intended to organize non-spatial data for describing the process. The site selection of railway is the process of finding locations that meet the desired conditions set by the selection criteria. For this issue a professional knowhow to deal with data depending on multi criteria is necessary to achieve of the task of decision making. Due to the tangle of the issue, a special effort must be done, to have a good usefulness of site selection. The results of spatial model in this paper shows the best railway track is (Karbala-ALhindya).
\end{abstract}

\section{Introduction}

Rail transportation is a critical method of transport all through the world. Every day, it transports a great many travellers and products from one point to another. The present levels of urbanization inside Karbala have prompted expanded populace inside the city most dwelling in regions around Karbala. This has prompted an extraordinary request of transportation administrations which couldn't be met by the street transport as it were. The consequence of this popularity has constantly growled movement on significant streets and thruways. The administration henceforth must be focused on investigating elective means, including the development and change of the suburbanite rail framework in Karbala and environs. It is basic that workers know all the accessible and advantageous methods of transport to take with a specific end goal to touch base to their goal. With the change of rail framework, workers should have a rail data framework. This realizes the requirement for an open transport data framework. With the accessibility of the data framework, all the data required by the clients will be accessible to them at the snap of a finger. This will likewise put a conclusion to the uncertainty of suburbanites with respect to their vehicle needs. The organizers and supervisors of open transportation will have the capacity to settle on skilful choices about the suburbanite needs. The objective in a site choice venture is to locate the best area with fancied conditions that fulfil foreordained determination criteria. Location selection commonly includes two fundamental stages: (i) site screening (i.e., distinguishing proof of few applicant locales from a wide

*Corresponding author: amjednaser@gmail.com geographic region and a scope of choice components) and (ii) site assessment (i.e., inside and out examination of every candidate site to locate the most appropriate one). The selection procedure endeavours to upgrade various targets in deciding the appropriateness of a specific site for a characterized travel office. Such enhancement regularly includes a huge number of variables, some of the time negating [1]. A portion of the essential variables that add to the trouble of the best possible decision incorporate the presence of various conceivable choices inside a search for domain, numerous goals, destinations, assorted qualities of gatherings, and absence of quantitative measures of the factors impact, vulnerabilities with respect to effect timing and greatness. In addition to instabilities in regards to government impact on the selected procedure through enactments, vulnerabilities in regards to conceivable postponements of approval and development $[2,1]$. Geographic Information Systems (GIS), MultiCriteria Decision Making techniques (MCDM), and Expert Systems have broadly been utilized as a part of tackling site determination issues throughout the previous two decades [3, 4, and 5]. Be that as it may, each of these systems has its own particular impediments in tending to spatial information, which is crucial when one is managing spatial choice issues, for example, a site choice issue. For instance, the conventional MCDM strategies have been non-spatial. In any case, in a genuine circumstance it can barely be accepted that the whole review zone is spatially homogeneous, in light of the fact that the assessment criteria used to change crosswise over space. A changed approach has continued spreading, in which the three apparatuses are joined in a way so that the weakness of one instrument is supplemented by the quality of another. A GIS system is 
used to manipulate the spatial investigation required in the screening phase of candidate locales [1]. There are a few viewpoints to consider when managing the railroad condition. The most self-evident one may be the track, or all the more particularly the track geometry, which must meet the set necessities keeping in mind the end goal to secure a sheltered operation of trains [6].The significance of the region of Karbala from religious and monetary aspects is highly appreciated in Iraq. An extensive number of tourists visit the blessed hallowed places during the specified time as a rule and in particular specific religious events turn into an imperative vacationer nature of the basic financial and come back to the nation obliged to be enhanced and the improvement of foundation in the city. for the region is also known for its strategic importance in Iraq history where it contains holy shrines of Imam Hussain and his brother Imam Abbas Peace Be Upon Them. A conceivable arrangement that this venture tries to address, is the advancement of rail data system which would, in addition to other things, show spatial dissemination of proposed railroad tracks/stations inside Karbala and its environs along the current railroad lines; show reasonable destinations to construct new rail route stations. The objective of this paper is to make use of fundamentals and practical merits of the application of GIS in the railway project management and selection of the most suitable site for the railway. Additionally, this paper can be considered as milestone for such projects. The site must be ideally chosen meaning it must be well disposed with condition, far into rural territories, close to a populated region choosing the best site for a railroad venture is not a simple undertaking. The analysis must consider financial, statistic and physical criteria and the truth of the review zone, and in addition the arrangements of governments and past involvement in this confused undertaking $[7,8]$. The principle target is to make a Geodatabase of the railroad lines that will empower capacity of data about rail route lines and to do their spatial investigation to decide their reasonableness according to their area and dissemination.

Specific objectives:

-To map the spatial distribution of the existing and proposed railway lines within the study area.

-To create a comprehensive database containing attributes of the railway lines.

-To produce the suitability of railway maps.

-To propose suitable sites for additional railway lines.

\section{Study area}

The Karbala City lies in the heart of the Iraqi state; it is located in the south-west of Baghdad, and is bordered to the north and from the west Unbar city, while bordering to the south of Najaf province, and is bordered by the city of Babylon from the north and northeast. There are many primary and secondary roads and rural roads, which are used by visitor to reach the city of Karbala, and despite the fact that the majority of the roads are unpaved, are well suited to use. Nevertheless, they are used in many cases especially in times of religious events taking place which draws visitors in large numbers to this province, and calls for the need to embark on many of these roads because of the great momentum in the main roads.

\section{Methods}

The model of a reasonableness site was assembled utilizing a model builder in ArcGIS 10.5. It was constructed in view of the MCE methodology known as the multi-criteria evaluation in which the weight of the relative significance found to every criterion and an aggregate score is then led for every paradigm by multiplying the relative significance percentage by the scale an incentive for that criterion (Figure 1). The appropriate maps were produced by coordinating different models [9, 10, and 11].

The main phases of the methodology used in the study area:

a) Data acquisition through authority printed reports.

b) Converting data into geometric elements through GIS.

c) Data interpretation and analysis.

d) Model development and extraction of measurements from analyses.

While choosing a site for a railroad line, there ought to be sufficient land accessible for the station building, for the proposed line as well as for any future development. The proposed region ought to likewise be with no religious structures. The proposed site ought to ideally be on a fairly level ground with great drainage infrastructures. It ought to be conceivable to give the greatest allowable grade in the yard. The station site ought to ideally have a straight arrangement so that the different signs are plainly unmistakable. The closeness of the station site to a bend creates various operational issues. The station site ought to be effectively available. The site ought to be close to towns and villages. Closeby towns ought to be associated with the station by methods for approach streets for the comfort of travelers. While choosing the site, it ought to be checked that satisfactory water supply is accessible for travelers and operational needs.

The railway determination relies upon number of criteria, including [2]:

-The railroad track would be situated close to residential areas to serve the number of inhabitants in these districts. -The railroad track would be situated far from agricultural areas.

- Railway track would be situated close to freeways.

- Railway track should be less crossing with an inner street system of the city.

-Railway way should be flat area the tolerated slope is $(0-10) \%$.

-Do not cross a railroad track with crucial establishments or infrastructure.

Data extraction is the way of creating more information from effectively arranged details. In the information input stage, utilizing the GIS need to: 
1. Layer represented road network inside the city of Karbala.

2. Expressway network layers.

3. Recent Satellite imagery for Karbala city.

4. Digital Terrain Model.

At that point utilize an ArcMap program and spatial extensions to pick the best area for the track of the railroad by recognizing purposes of arrange framework and include them in the characteristic procedure.

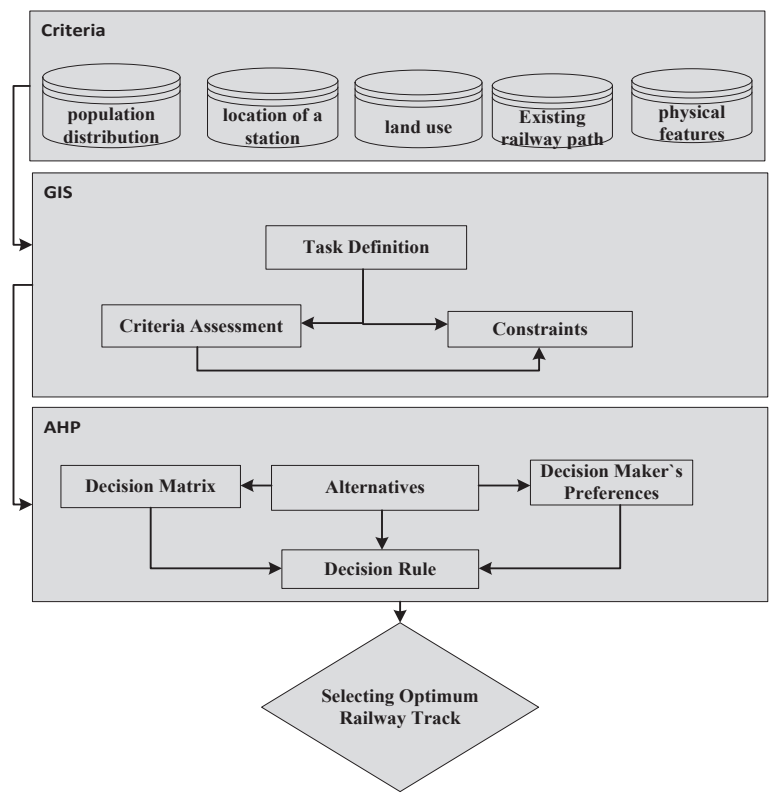

Fig. 1. Methodological schema.

\section{Results and discussion}

After extracting required datasets, they were reclassified and last stride the layers were weighted utilizing Analytic Hierarchy Process (AHP). The Analytic Hierarchy Process (AHP) is one of the more well-known basic leadership methods that are broadly used to address Multi-Criteria Decision- Making (MCDM) issues. This technique separates the issue into a chain of command of sub-issues. At that point from the inspired judgments from specialists on the near execution or criticality of the sub-issues, needs are computed. These needs empower the basic leadership identified with sorting, positioning or choosing the most reasonable option in MCDM issues. ArcGIS Spatial Analyst gives a rich arrangement of tools to perform cell-based (raster) investigation. Of the three sorts of GIS data (raster, vector, and TIN), the raster information structure is the most complete displaying condition for spatial investigation. There are two principle approaches to perform separate examination in ArcGIS Spatial Analyst: Euclidean distance and cost distance. The Euclidean distance capacities measure straight-line distance from every cell to the nearest source (the source recognizes the objects of intrigue, for example, wells, streets, or a school). The cost distance capacities (or cost weighted distance) changes Euclidean distance by comparing separation as a cost element, which is the cost to go through any given cell. The Euclidean Distance capacity is utilized habitually as an independent capacity for applications: this can be utilized while making a reasonableness guide, when information relating to the distance from a specific value is required. For this review, the distance of every railroad line was ascertained and the yield was in raster format.

\subsection{Site selection}

This phase in which, the final data representation in the form of thematic maps performed based on modelling process in GIS. The proposed railroad track for indicated criteria have been chosen and illustrated in as a type of maps (Figures 2-5).

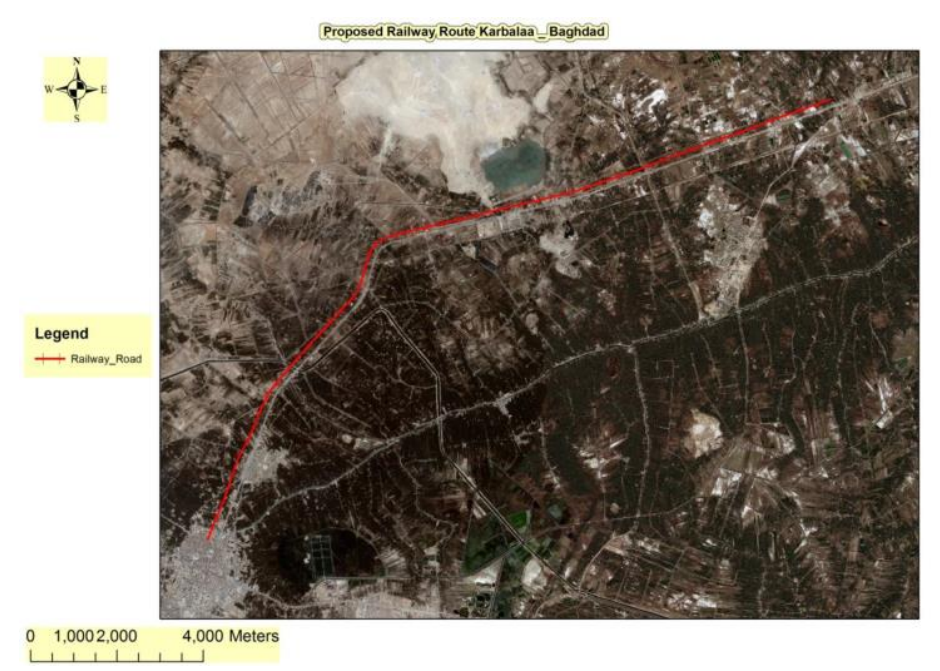

Fig. 2. Proposed railway route (Karbala - Baghdad).

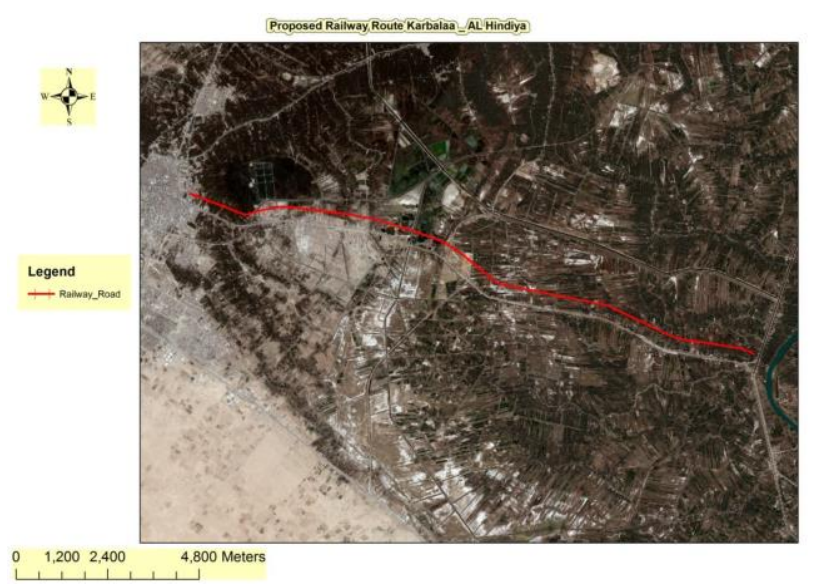

Fig. 3. Proposed railway route (Karbala - Hindya). 


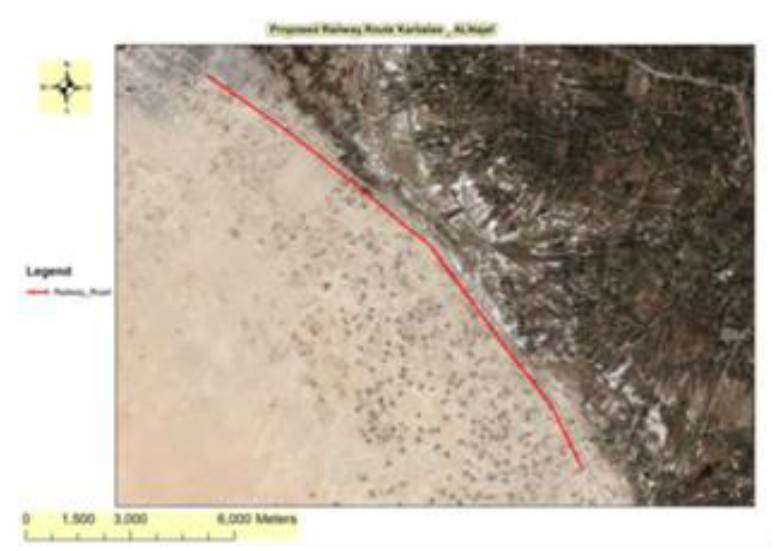

Fig. 4. Proposed railway route (Karbala - Najaf).

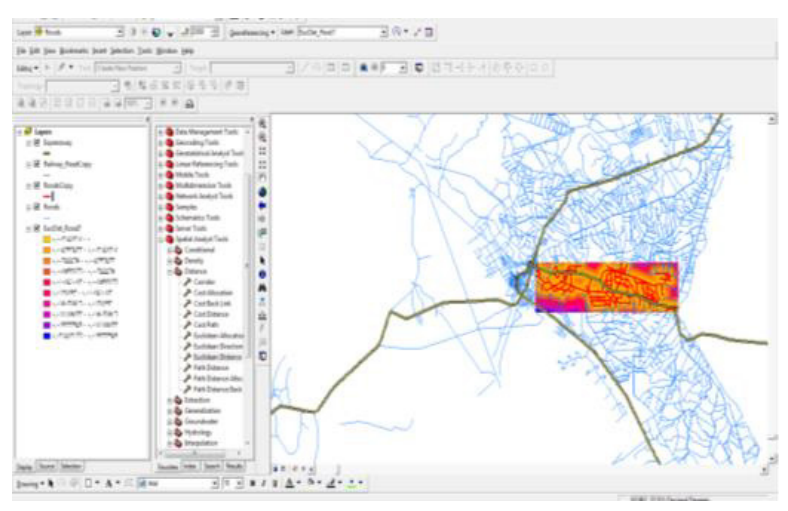

Fig. 5. Snapshot of proposed railway route (Karbala - Hindya).

\section{Conclusions}

This paper uses technique based on bridging the gap between all the criteria to determine suitable location for the railway. GIS is effective with tremendous usefulness in its applications when it is connected to decision making process. It is a tool that is extremely helpful in recognizing patterns and issues and finding answers for them. It represents the expressing picture on a guide presented with every one of the parameters related with it. The results of spatial analysis in this project shows the best railway track is (Karbala-ALhindya) because it is going through several residential areas, far from agricultural areas, the lack of a railway track list and is the main corridor for most visitors to the city.

\section{References}

[1] A. Farkas, Inter. Con. 7, (2009)

[2] W. Roets, (Doctoral dissertation),(2005)

[3] E. Briceño-Elizondo, D. Jäger, M. J. Lexer, J. Garcia-Gonzalo, H. Peltola, S. Kellomäki, Ecol. Indic. 8, (2008)

[4] S. Kalogirou, Comp, envir. and urban systems 26, (2002)

[5] I. Tsoy, LWREX. 6, (2015)

[6] E. Andreas, (2011).

[7] M. Bojesen, L. Boerboom, H. Skov-Petersen, Land use pol., 42, (2015)
[8] J.Irizarry, E. P. Karan, F.Jalaei, Auto.in Cons. 31, (2013).

[9] A. N. M. Al-Hameedawi, Integrative GI Technology Applied to Best-Site Selection for Industrial Areas in Erbil City, Iraq, TUDpress Ver. der Wiss. Dresden, (2014)

[10] S.Corrente, S. Greco, R. SłOwińSki, Decis. Sup. Sys. 53, (2012)

[11]D. Ergu, G. Kou, Y. Shi, Com. and Oper. Research, 42, (2014) 